\title{
Pharmacokinetics of Ampreloxetine, a Norepinephrine Reuptake Inhibitor, in Healthy Subjects and Adults with Attention-Deficit/ Hyperactive Disorder or Fibromyalgia Pain
}

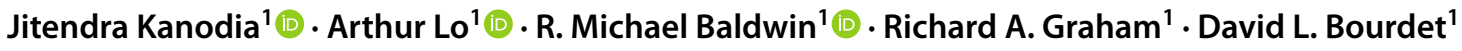

Published online: 27 August 2020

(c) The Author(s) 2020

\begin{abstract}
Background and Objective Ampreloxetine is a novel norepinephrine reuptake inhibitor in development for the treatment of symptomatic neurogenic orthostatic hypotension. The objectives of this analysis were to define the pharmacokinetics of once-daily oral ampreloxetine and provide dose recommendations for clinical development.

Methods We fitted a population pharmacokinetic model to ampreloxetine plasma concentrations from single- and multipleascending dose trials in healthy subjects and two phase II studies in adult subjects with attention-deficit/hyperactive disorder or fibromyalgia at doses of $2-50 \mathrm{mg}$.

Results Ampreloxetine pharmacokinetics was best described by a two-compartment model with first-order absorption and elimination. The terminal half-life was 30-40 h, resulting in sustained drug concentrations for the entire 24-h dosing interval at steady state. Covariates of age, weight, or renal impairment did not impact ampreloxetine exposure. Cytochrome P450 2D6 phenotype had no influence on ampreloxetine exposure. Sex and smoking status were identified as statistically significant covariates, suggesting a role for cytochrome P450 1A2 in the elimination of ampreloxetine. Despite statistical significance, differences in ampreloxetine exposure in male vs female subjects and smokers vs non-smokers were not clinically meaningful at the recommended dose. At the 10-mg dose, $>75 \%$ norepinephrine transporter inhibition and $<50 \%$ serotonin transporter inhibition are anticipated for adult subjects.

Conclusions The population pharmacokinetic model effectively described the plasma concentration-time profile of ampreloxetine after single and multiple doses. Population pharmacokinetic/pharmacodynamic analysis justified using a fixed dosing regimen with no dose adjustments across a broad population and can be used to inform dosing strategies in future clinical studies.
\end{abstract}

Clinical Trial Registration ClinicalTrials.gov identifier numbers NCT01693692 (fibromyalgia); NCT01458340 (attentiondeficit/hyperactive disorder).

\section{Key Points}

Pharmacokinetic analysis of plasma ampreloxetine expo-

Jitendra Kanodia and Arthur Lo contributed equally to this article.

R. Michael Baldwin: Former employee of Theravance Biopharma US, Inc.

Electronic supplementary material The online version of this article (https://doi.org/10.1007/s40262-020-00918-7) contains supplementary material, which is available to authorized users.

Jitendra Kanodia

jkanodia@theravance.com

Clinical and Translational Pharmacology, Theravance Biopharma US, Inc, 901 Gateway Boulevard,

South San Francisco, CA 94080, USA sure indicated that the terminal half-life was 30-40 h, reached steady state after 6 days, and accumulated threeto four-fold with once-daily dosing.

Population pharmacokinetic modeling identified sex and smoking status as statistically significant covariates indicating that cytochrome P450 1A2-based metabolism is the key mechanism for ampreloxetine elimination.

Based on the pharmacokinetic/pharmacodynamic relationship, a once-daily ampreloxetine dose of $10 \mathrm{mg}$ is predicted to achieve sustained norepinephrine transporter engagement during the entire dosing interval. 


\section{Introduction}

Ampreloxetine (previously known as TD-9855) is a novel small-molecule inhibitor of both norepinephrine (NE) and serotonin (5-HT) uptake, with selectivity for NE [1]. Based on the results of both non-clinical [2] and human [3] studies, ampreloxetine is anticipated to offer benefits for the management of symptomatic neurogenic orthostatic hypotension $(\mathrm{nOH})$. Symptomatic nOH remains largely unaddressed by current therapies [4-7]. The pressor agents, fludrocortisone [5], a synthetic mineralocorticoid, midodrine, an $\alpha_{1}$ adrenergic receptor agonist approved for the treatment of orthostatic hypotension [6], and droxidopa, an NE precursor approved in the USA for the treatment of $\mathrm{nOH}$ [7], are effective in acutely treating declines in blood pressure but lack durability of effect in treating the debilitating symptoms of $\mathrm{nOH}$ [8-12]. Moreover, midodrine and droxidopa have short half-lives and require multiple doses per day [6, 7].

Pharmacological inhibitors of NE transporters (NETs) afford an opportunity to treat the core symptoms of $\mathrm{nOH}$ that are attributable to the variety of underlying neurological disorders (e.g., synucleinopathies, such as multiple system atrophy, Parkinson's disease, or pure autonomic failure) [4]. Norepinephrine transporter inhibitors are anticipated to be beneficial in the treatment of $\mathrm{nOH}$ through potentiation of residual sympathetic tone that support positional changes from supine to standing [2, 13]. Atomoxetine, an NET inhibitor approved in the USA for the treatment of attentiondeficit/hyperactivity disorder (ADHD) [13], has been evaluated in a proof-of-concept clinical study for the treatment of $\mathrm{nOH}$, with results suggestive of symptomatic benefits in patients with $\mathrm{nOH}$ [14].

The pharmacological and pharmacokinetic behavior of ampreloxetine has been studied in previous clinical trials. An absorption, metabolism, and excretion study of [14C]ampreloxetine was conducted in six healthy male volunteers after a single oral administration of $20 \mathrm{mg}(100 \mu \mathrm{Ci})$ of ampreloxetine [15]. Ampreloxetine elimination is primarily driven by metabolism, as less than $5 \%$ of the dose was recovered in urine and feces as unchanged drug. Furthermore, ampreloxetine has been evaluated in healthy male subjects to assess NET and serotonin transporter occupancy in the human brain using positron emission tomography after administration of oral doses from 4 to $20 \mathrm{mg}$ [1]. The results of the positron emission tomography study demonstrated NET occupancy to be predominant (NET $>$ serotonin transporter) and a concentration-dependent increase in NET occupancy with increasing ampreloxetine plasma concentrations over the tested dose range. Limited serotonin transporter occupancy was observed at the highest evaluated dose $(20 \mathrm{mg}), 25 \%( \pm 8 \%)$ at a plasma concentration of 6.8 $\mathrm{ng} / \mathrm{mL}$ [1]. The relationship between plasma ampreloxetine concentration and NET occupancy data was well described by an $E_{\max }$ model, with an ampreloxetine plasma concentration of $1.2 \mathrm{ng} / \mathrm{mL}$ (95\% confidence interval $0.76-1.7 \mathrm{ng} / \mathrm{mL}$ ) predicted to yield $50 \%$ occupancy of NET within the brain.

The objectives of this analysis were to define the pharmacokinetics of ampreloxetine in healthy volunteers and subjects with ADHD and fibromyalgia (FM) and identify any covariates or special populations to inform the dosing strategy for further clinical development.

\section{Materials and Methods}

\subsection{Ethical Conduct of the Study}

All procedures performed in studies involving human participants were in accordance with the ethical standards of the institutional and/or national research committee, the 1964 Helsinki Declaration and its later amendments, and Good Clinical Practice [16]. The trial protocols were approved by independent ethics committees and/or institutional review boards (single- and multiple-ascending dose studies, Independent Investigational Review Board, Inc., 6738 West Sunrise Blvd, Suite 102, Plantation, FL 33313, USA; ADHD and FM studies, Western Institutional Review Board ${ }^{\circledR}, 3535$ 7th Avenue, SW Olympia, WA 98502-5010, USA, and IntegReview 3001 S. Lamar Blvd, Suite 210, Austin, TX 78704, USA). All subjects provided written informed consent before initiation of any trial-related activities.

\subsection{Study Designs}

\subsubsection{Single-Ascending Dose}

A phase I, double-blind, randomized, placebo-controlled, single-ascending dose (SAD) study of ampreloxetine was conducted to evaluate the pharmacokinetic ( $\mathrm{PK}$ ) profile in healthy male and female subjects. A total of 40 subjects were enrolled in this study into five sequential cohorts $(n=$ $8 /$ cohort) to receive a single oral dose of either ampreloxetine $(2,4,8,20$, or $50 \mathrm{mg})$ or placebo after $8 \mathrm{~h}$ of fasting, in a ratio of $6: 2$ active drug to placebo. No concomitant medications were allowed during the course of this study.

In all cohorts, blood samples for measurement of ampreloxetine concentration were collected pre-dose and at $0.5,1,1.5,2,3,3.5,4,6,8,10,12,24,36,48$, and $72 \mathrm{~h}$ post-dose. Based on plasma half-life and time to maximum concentration values observed in cohort 1 , additional blood samples were collected at 14 and $96 \mathrm{~h}$ post-dose in cohort 2 , and at 14,96 , and 144 h post-dose in cohorts 3,4 , and 5 . 


\subsubsection{Multiple-Ascending Dose}

A phase I, double-blind, randomized, placebo-controlled, multiple-ascending dose (MAD) study was conducted to evaluate the safety and pharmacokinetics of multiple doses of ampreloxetine in healthy subjects aged $18-55$ years and in an additional cohort of healthy subjects aged 56-65 years. Thirty-two subjects aged 18-55 years and eight subjects aged 56-65 years were enrolled in this study; thus, a total of 40 subjects were randomized into five sequential cohorts $(n=8 /$ cohort). Within each cohort, subjects were randomized to receive either ampreloxetine or placebo, in a ratio of 6:2 active drug to placebo. In cohorts 1,2 , and 3 , ampreloxetine doses of $4 \mathrm{mg}, 10 \mathrm{mg}$, and $20 \mathrm{mg}$ were administered orally once daily for 14 days, respectively, in subjects aged $18-55$ years. Cohort 4 received ampreloxetine $20 \mathrm{mg}$ once daily for 14 days in subjects aged 56-65 years. In cohort 5, dose titration was explored, starting with $20 \mathrm{mg}$ of ampreloxetine administered once daily for 3 days followed by $40 \mathrm{mg}$ administered once daily for 14 days, in subjects aged 18-55 years. No concomitant medications were allowed during the course of this study.

In cohorts 1-4, PK blood samples for assays of ampreloxetine were collected on days 1 and 14 at pre-dose and at 0.5 , $1,2,4,6,8,10,12$, and $14 \mathrm{~h}$ post-dose. Additional samples were collected after the day 14 dose at $24,48,72$, and $96 \mathrm{~h}$ post-dose. Trough samples were collected pre-dose on days $2,4,6,8,10$, and 12 . In cohort 5 , during the 3 days at the 20-mg dose level, PK blood samples were collected at predose and $10 \mathrm{~h}$ post-dose on day 1 , and at pre-dose on day 2 . Following escalation to the 40-mg dose level, serial, trough, and post-dose samples were collected on the same schedule as in cohorts $1-4$.

To evaluate the effect of food on the pharmacokinetics of ampreloxetine, following the 14 days of ampreloxetine administration and an additional 14-day washout period, subjects in cohort 1 were administered a single oral dose of ampreloxetine $30 \mathrm{~min}$ after eating a high-fat meal [17]. Pharmacokinetic sample times mirrored the sampling following the day 14 dose.

\subsubsection{Attention-Deficit/Hyperactivity Disorder Study}

A phase II, double-blind, placebo-controlled, parallelgroup, three-arm, randomized study (NCT01458340) was conducted to compare $5 \mathrm{mg}$ and $20 \mathrm{mg}$ of ampreloxetine with placebo in 285 adult subjects with clinically confirmed ADHD according to the Adult Attention-Deficit/Hyperactivity Disorder Clinical Diagnostic Scale (ACDS Version 1.2) [18]. Eligible subjects were randomized equally to receive either active treatment or placebo daily for 6 weeks. Subjects in the ampreloxetine 5-mg or placebo arm received ampreloxetine $5 \mathrm{mg}$ or placebo once daily for 6 weeks. Subjects in the ampreloxetine 20-mg arm received an initial dose of $10 \mathrm{mg}$ once daily for 1 week, followed by $20 \mathrm{mg}$ once daily for 5 weeks. Each subject's dose was increased to $20 \mathrm{mg}$ unless a safety or tolerability concern was identified during the 10-mg once-daily dosing week, in which case the subjects continued to receive $10 \mathrm{mg}$ once daily for a total of 6 weeks. Blood samples for the measurement of ampreloxetine plasma concentration were obtained on study days $8,15,29$, and 43 . On study days 15 and 43 , the samples were obtained between 2 and $10 \mathrm{~h}$ post-dose. Cytochrome P450 (CYP) 2D6 genotype and phenotype were assigned using the AmpliChip CYP450 test (Roche Molecular Diagnostics, Branchburg, NJ, USA) based on the manufacturer's algorithm. Polymorphisms in CYP2D6 have been shown to be associated with significant differences in the PK profile for CYP2D6 substrate drugs [19].

\subsubsection{Fibromyalgia Study}

A phase II multicenter, randomized, double-blind, parallelgroup, placebo-controlled study (NCT01693692) was conducted to compare a lower-dose regimen ( $2.5 \mathrm{mg}$ once daily for 1 week, followed by $5 \mathrm{mg}$ once daily for 5 weeks) and a higher-dose regimen (10 mg once daily for 1 week, followed by $20 \mathrm{mg}$ once daily for 5 weeks) of ampreloxetine vs placebo in approximately 375 adult subjects with FM according to the American College of Rheumatology diagnostic criteria for FM [20]. Blood samples for measurement of ampreloxetine plasma concentrations were obtained on study days $8,15,29$, and 43 (end of treatment). Blood samples were taken before dosing on days 8,29 , and 43 and at any time between 2 and $10 \mathrm{~h}$ post-dose on day 15 .

\subsection{Pharmacokinetic Analyses}

\subsubsection{Bioanalysis of Pharmacokinetic Samples}

Plasma samples were assayed using a validated liquid chromatography with tandem mass spectrometry method at Advion/Quintiles (Ithaca, NY, USA). The ampreloxetine assay quantification range was $0.05-100 \mathrm{ng} / \mathrm{mL}$ in all studies. Overall precision for the calibration standards and quality-control samples, as measured by coefficient of variation (\%), was always within $10 \%$.

\subsubsection{Non-Compartmental Analysis}

Non-compartmental analysis of the SAD and MAD studies was conducted using WinNonLin Version 5.2 (Pharsight Corporation, Sunnyvale, CA, USA). Reported PK parameters include maximum concentration $\left(C_{\max }\right)$, time 
to maximum concentration, lag time, terminal elimination half-life, oral volume of distribution during terminal phase, oral clearance $(\mathrm{CL} / \mathrm{F})$, area under the concentration-time curve (AUC) from time 0 to $24 \mathrm{~h}\left(\mathrm{AUC}_{0-24}\right)$, and $0 \mathrm{~h}$ to time $t\left(\mathrm{AUC}_{0-t}\right)$. The effect of food was assessed descriptively by examining the mean $C_{\max }$ and $\mathrm{AUC}_{0-24}$ in cohort 1 on day 29 (fed state) relative to the mean $C_{\max }$ and $\mathrm{AUC}_{0-24}$ values in cohort 1 on day 1 (fasted state).

\subsubsection{Population Pharmacokinetic Analysis}

Data from the phase I SAD/MAD and phase II studies were combined into a single dataset containing individual demographics and time course of plasma ampreloxetine concentrations. A total of 2978 ampreloxetine concentrations from 499 subjects were used to conduct a non-linear mixed-effects modeling analysis and identify sources of intra- and inter-individual variability. A two-compartment model best described the ampreloxetine PK profile collected from the phase I SAD/MAD studies. The models assumed a log-normal distribution of the individual PK parameters and a mixed residual error model. Models were evaluated using the objective function value, computed as -2 times the loglikelihood, diagnostic plots, and the precision of parameter estimates. All analysis was conducted using NONMEM 7.2 (Icon plc, Dublin, Ireland) using the first-order conditional estimation method.

A covariate analysis was conducted to identify the effects of age, weight, creatinine clearance (as continuous covariates using exponential models of inter-individual variation), sex, and smoking status (as categorical covariates using an additive model) on the apparent $\mathrm{CL} / \mathrm{F}$ of ampreloxetine and volume of the central compartment $\left(V_{1} / F\right)$. Identification of statistically significant covariates was conducted using a stepwise-forward selection with an $\alpha=0.01$ (a decrease of 6.63 points in the objective function) and a stepwise-backward elimination process with an $\alpha=0.001$ (an increase of 10.83 points in the objective function). Model fit was evaluated using goodness-of-fit plots and visual predictive checks.

The exposure to ampreloxetine was simulated for each subject using the individual post hoc PK parameters from the final population PK model to determine the clinical significance of the statistically significant covariates. The post hoc exposures were also used to determine whether ampreloxetine exposure remained consistent across the healthy, ADHD, and FM patient populations. Differences in ampreloxetine plasma exposure between poor, intermediate, extensive, and ultra-rapid CYP2D6 metabolizers was evaluated using a one-way analysis of variance test of the log-transformed AUC values across each group.

\subsubsection{Population Pharmacokinetic-Pharmacodynamic Simulation}

The individually estimated PK parameters determined by the population PK analysis were used to simulate the steadystate concentration-time profiles for each subject in the dataset at two doses of ampreloxetine (5 $\mathrm{mg}$ once daily and $10 \mathrm{mg}$ once daily). The steady state $\mathrm{AUC}_{0-24}$ was calculated for each simulated subject using the linear trapezoidal rule.

Simulated individual plasma concentration-time profiles and the pharmacodynamic model established from the positron emission tomography study (half maximal inhibitory concentration $=1.2 \mathrm{ng} / \mathrm{mL}$ ) were subsequently used to predict the time course of NET occupancy. The predicted NET occupancy after multiple doses of ampreloxetine was averaged over the 24-h dosing interval to assess the steady-state level of NET inhibition.

\section{Results}

\subsection{Ampreloxetine Pharmacokinetic Profile in Healthy Volunteers}

Ampreloxetine PK assessments following single oral-dose administration based on non-compartmental analysis are presented in Table 1 and mean plasma concentrations of ampreloxetine over time areplotted in Fig. 1a, b. Plasma concentration-time profiles were characterized by an initial lag in the absorption phase with a median lag time value range of $0.5-1.0 \mathrm{~h}$, followed by a prolonged absorption phase with a median time to maximum concentration value range of 8-12 h post-dose (Fig. 1a, Table 1). Mean ampreloxetine terminal half-life values had a range of 29.5-41.0 h. Exposure to ampreloxetine in plasma increased in a dose-proportional manner across a dose range of $2-50 \mathrm{mg}$.

Ampreloxetine PK assessments, following 14 days of once-daily dosing based on a non-compartmental analysis, are presented in Table 2 and mean plasma concentrations of ampreloxetine after once-daily administration for 14 days are presented in Fig. 1b. Steady-state plasma concentrations of ampreloxetine were achieved by day 6 in most subjects after once-daily doses of 4-40 mg (Table 2). Accordingly, the ampreloxetine PK profile on day 14 represents steady-state behavior. Oral clearance estimates following multiple dosing are more robust than those determined after a single dose owing to a large percentage ( $>20 \%)$ of the $\mathrm{AUC}_{0 \text {-inf }}$ that was extrapolated in some subjects in the single-dose study. After reaching $C_{\max }$, plasma concentrations of ampreloxetine declined with the mean half-life range of 34.3-43.1 h at steady state. Consistent with the half-life, mean accumulation ratios were based on the $\mathrm{AUC}_{0-24}$ range of 3.18- to 
Table 1 Summary of mean (standard deviation [SD]) plasma pharmacokinetic parameters for ampreloxetine: single-ascending dose study

\begin{tabular}{|c|c|c|c|c|c|c|c|c|c|}
\hline $\begin{array}{l}\text { Dose level } \\
(\mathrm{mg})\end{array}$ & & $C_{\max }(\mathrm{ng} / \mathrm{mL})$ & $T_{\max }{ }^{\mathrm{a}}(\mathrm{h})$ & $T_{\text {lag }}{ }^{\mathrm{a}}(\mathrm{h})$ & $\begin{array}{l}\mathrm{AUC}_{0-24} \\
(\mathrm{ng} * \mathrm{~h} / \mathrm{mL})\end{array}$ & $\begin{array}{l}\mathrm{AUC}_{0-\mathrm{t}} \\
(\mathrm{ng} * \mathrm{~h} / \mathrm{mL})\end{array}$ & $t_{1 / 2}(\mathrm{~h})$ & $\mathrm{CL} / \mathrm{F}(\mathrm{L} / \mathrm{h})$ & $V_{\mathrm{Z}} / F(\mathrm{~L})$ \\
\hline \multirow[t]{3}{*}{2} & Mean & 0.925 & 12 & 1 & 15.8 & 36.3 & 29.5 & 56.4 & 2397 \\
\hline & $\mathrm{SD}$ & 0.335 & $8.00,12.0$ & $0.5,1.5$ & 5.6 & 11.1 & 4.6 & 22.3 & 916 \\
\hline & $n$ & 6 & 6 & 6 & 6 & 6 & 3 & 3 & 3 \\
\hline \multirow[t]{3}{*}{4} & Mean & 2.09 & 8 & 1 & 32.8 & 87.6 & 36.0 & 38.7 & 1983 \\
\hline & SD & 0.34 & $8.00,10.0$ & $0.5,1.0$ & 4.3 & 11.4 & 6.4 & 6.4 & 353 \\
\hline & $n$ & 6 & 6 & 6 & 6 & 6 & 6 & 6 & 6 \\
\hline \multirow[t]{3}{*}{8} & Mean & 5.02 & 12 & 0.50 & 85.6 & 231 & 34.5 & 38.2 & 1659 \\
\hline & SD & 1.4 & $8.05,14.0$ & $0,1.0$ & 22.5 & 98 & 12.8 & 17.4 & 386 \\
\hline & $n$ & 6 & 6 & 6 & 6 & 6 & 6 & 6 & 6 \\
\hline \multirow[t]{3}{*}{20} & Mean & 8.59 & 12 & 0.5 & 142 & 445 & 41.0 & 52.2 & 2745 \\
\hline & SD & 2.45 & $8.00,14.0$ & $0,2.0$ & 43 & 195 & 12.2 & 33.8 & 1034 \\
\hline & $n$ & 6 & 6 & 6 & 6 & 6 & 6 & 6 & 6 \\
\hline \multirow[t]{3}{*}{50} & Mean & 26.4 & 12 & 0.5 & 461 & 1430 & 40.9 & 39.9 & 2337 \\
\hline & SD & 5.7 & $8.00,14.0$ & $0,1.0$ & 105 & 530 & 8.8 & 15 & 1046 \\
\hline & $n$ & 6 & 6 & 6 & 6 & 6 & 5 & 5 & 5 \\
\hline
\end{tabular}

In each cohort, 6 subjects were dosed with the active drug

$A U C_{0-24}$ area under the concentration-time curve from time 0 to $24 \mathrm{~h}, A U C_{0-t}$ area under the concentration-time curve from time 0 to the time of last quantifiable concentration, $C L / F$ oral clearance, $C_{\max }$ maximum concentration, $t_{1 / 2}$ terminal elimination half-life, $T_{\text {lag }}$ lag time, $T_{\max }$ time to maximum concentration, $V_{Z} / F$ oral volume of distribution during terminal phase

${ }^{a}$ Median (minimum, maximum)

4.38-fold at steady state. Consistent with the single-dose PK profile, plasma exposure at steady state also increased in an approximate dose-proportional manner at a dose range of 4-40 mg (Table 2, Table 1 of the Electronic Supplementary Material [ESM], and Fig. 1b). Mean $C_{\max }$ and $\mathrm{AUC}_{0-24}$ were $9.4 \%$ and $6.5 \%$ lower, respectively, in the fed state compared with the fasted state. These differences are considerably lower than the magnitude of inter-individual variability in $C_{\text {max }}$ and $\mathrm{AUC}_{0-24}$ and are therefore not anticipated to be clinically meaningful (Table 1 of the ESM).

At the 20-mg dose level, ampreloxetine exposure in subjects aged 56-65 years was approximately $35 \%$ and $70 \%$ higher on days 1 and 14, respectively, when compared with adult subjects aged 18-55 years who were administered the same 20-mg dose (Table 2 and Table 1 of the ESM). However, the ampreloxetine 20-mg older group consisted entirely of female subjects $(n=6)$, compared with three male subjects and three female subjects in the ampreloxetine 20-mg adult reference group. Accordingly, the impact of age or sex on ampreloxetine pharmacokinetics could not be differentiated in this study.

\subsection{Ampreloxetine Pharmacokinetics in Subjects with Attention-Deficit/Hyperactivity Disorder and Fibromyalgia}

After continuous once-daily dosing of ampreloxetine in the phase II study in subjects with ADHD, mean ampreloxetine plasma concentrations were generally consistent with exposures observed in the SAD and MAD studies. Mean plasma concentrations at steady state had a range from 4.5 $\mathrm{ng} / \mathrm{mL}$ (day 8) to $5.1 \mathrm{ng} / \mathrm{mL}$ (day 15 ) in the ampreloxetine 5-mg treatment arm (Table 3). Subjects in the 20-mg treatment arm received a once-daily dose of $10 \mathrm{mg}$ from day 1 to day 7. Subjects who were not escalated to $20 \mathrm{mg}$ and continued to receive $10 \mathrm{mg}$ up to day 42 had mean plasma concentrations at steady state from $12.0 \mathrm{ng} / \mathrm{mL}$ (day 29) to 13.4 $\mathrm{ng} / \mathrm{mL}$ (day 8). Subjects who were escalated to $20 \mathrm{mg}$ had a mean plasma concentration at the steady-state range from $18.2 \mathrm{ng} / \mathrm{mL}$ (day 43) to $20.3 \mathrm{ng} / \mathrm{mL}$ (day 29) (Table 3). No statistical difference in ampreloxetine plasma exposure was observed between poor, intermediate, extensive, and ultra-rapid CYP2D6 metabolizers within each dose level at each timepoint based on a one-way analysis of variance test $(p>0.05)$ (Fig. 1c).

After continuous once-daily dosing of ampreloxetine in the phase II study in subjects with FM, ampreloxetine concentrations were consistent with observed concentrations in the SAD, MAD, and phase II ADHD studies (Table 3). In the 5-mg and 20-mg treatment arms, mean ampreloxetine plasma concentrations were $5.3 \mathrm{ng} / \mathrm{mL}$ (day 43) to 6.3 $\mathrm{ng} / \mathrm{mL}$ (day 15) and $21.0 \mathrm{ng} / \mathrm{mL}$ (day 43) to $28.0 \mathrm{ng} / \mathrm{mL}$ (day 15), respectively, at steady state (Table 4).

\subsection{Population Pharmacokinetic Analysis}

The pooled PK dataset consisted of demographics and plasma concentrations from 499 subjects (Table 2 of the 

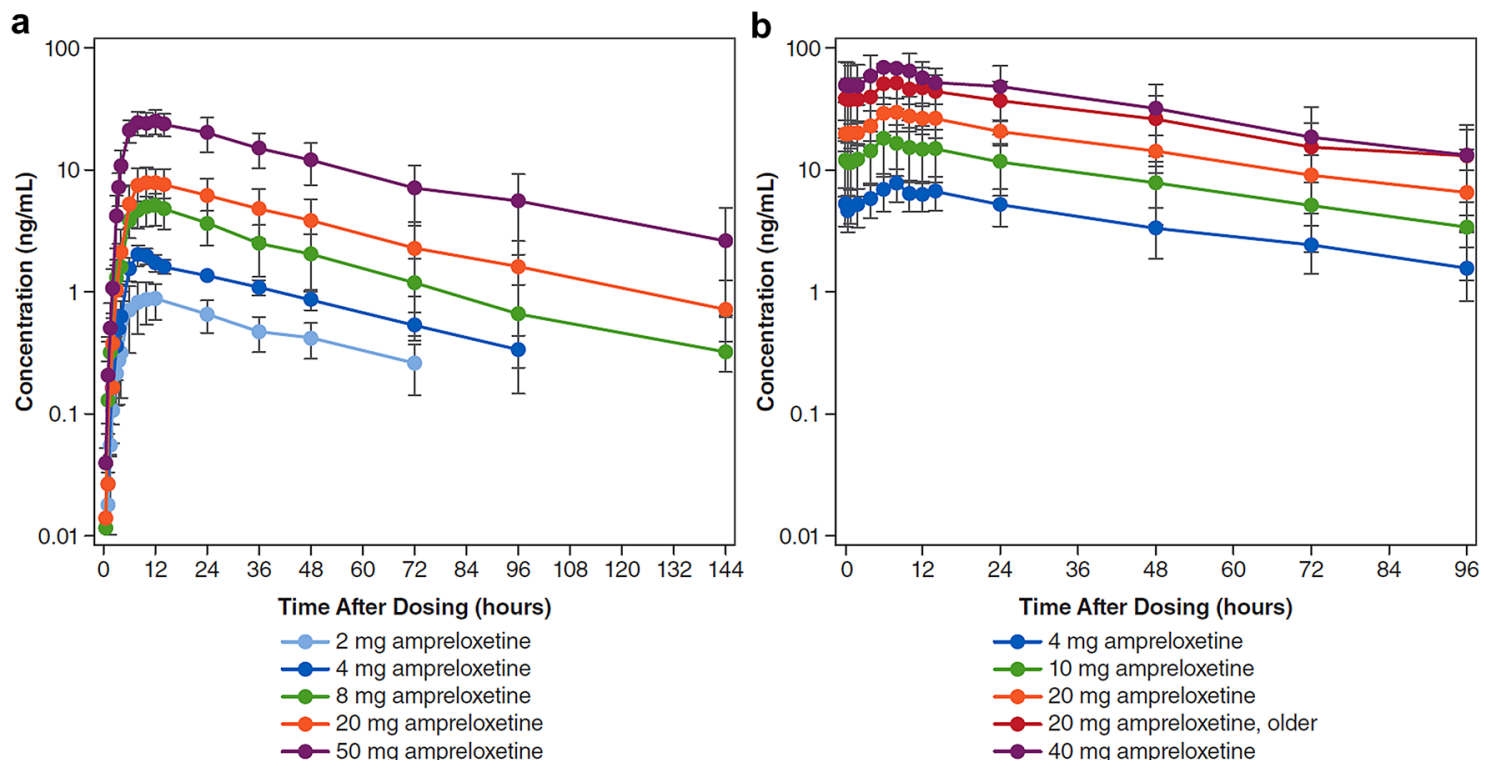

C

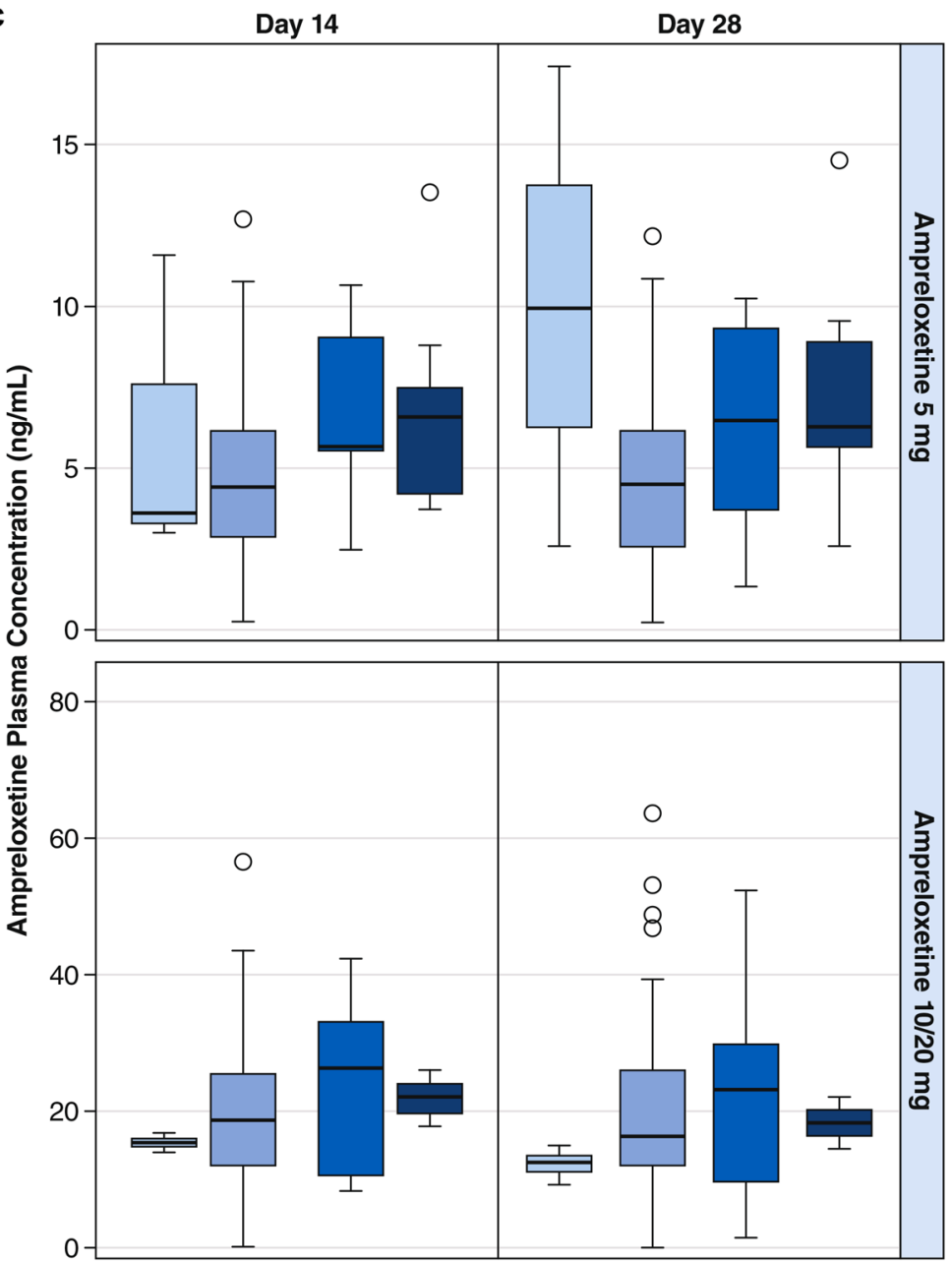

CYP2D6 Phenotype 白 Ultrarapid Metabolizer Extensive Metabolizer Intermediate Metabolizer Poor Metabolizer

Fig. 1 Mean plasma concentrations of ampreloxetine: a day 1 of single-ascending dose (SAD) study, b day 14 of multiple-ascending dose (MAD) study, and $\mathbf{c}$ attention-deficit/hyperactivity disorder study grouped by cytochrome P450 (CYP) 2D6 phenotype 
Table 2 Summary of plasma pharmacokinetic parameters for ampreloxetine: multiple-ascending dose study (day $14^{\mathrm{a}}$ )

\begin{tabular}{|c|c|c|c|c|c|c|c|c|c|c|c|c|c|}
\hline \multirow[t]{2}{*}{ Dose level (mg) } & & \multirow[t]{2}{*}{$C_{\max }(\mathrm{ng} / \mathrm{mL})$} & \multirow[t]{2}{*}{$T_{\max }^{\mathrm{b}}(\mathrm{h})$} & \multirow{2}{*}{$\begin{array}{l}\mathrm{AUC}_{0-4} \\
\text { (ng*h/ } \\
\mathrm{mL})\end{array}$} & \multirow[t]{2}{*}{$t_{1 / 2}(\mathrm{~h})$} & \multirow[t]{2}{*}{$\mathrm{CL} / \mathrm{F}(\mathrm{L} / \mathrm{h})$} & \multirow[t]{2}{*}{$V_{\mathrm{Z}} / F(\mathrm{~L})$} & \multirow[t]{2}{*}{$\mathrm{AR}$} & \multicolumn{5}{|c|}{$C_{\text {trough }}(\mathrm{ng} / \mathrm{mL})$} \\
\hline & & & & & & & & & Day 4 & Day 6 & Day 8 & Day 10 & Day 12 \\
\hline \multirow[t]{3}{*}{4} & Mean & 7.88 & 8 & 150 & 43.1 & 29.9 & 1833 & 4.98 & 3.4 & 4.03 & 4.16 & 4.67 & 4.47 \\
\hline & SD & 2.39 & $8.00,8.00$ & 47 & 4.1 & 13.2 & 737 & 0.84 & 1.09 & 1.46 & 1.39 & 1.61 & 1.47 \\
\hline & $n$ & 5 & 5 & 5 & 5 & 5 & 5 & 5 & 6 & 6 & 5 & 5 & 5 \\
\hline \multirow[t]{3}{*}{10} & Mean & 18.2 & 6.01 & 336 & 37.7 & 36.4 & 1880 & 3.18 & 8.36 & 12.3 & 13.1 & 12.1 & 11.5 \\
\hline & SD & 8.7 & $6.00,8.00$ & 156 & 6.2 & 17.7 & 726 & 0.45 & 3.56 & 6.8 & 6.4 & 5.7 & 5.6 \\
\hline & $n$ & 6 & 6 & 6 & 6 & 6 & 6 & 6 & 6 & 6 & 6 & 6 & 6 \\
\hline \multirow[t]{3}{*}{20} & Mean & 30.5 & 8 & 600 & 37.6 & 35.7 & 2068 & 3.74 & 14.6 & 18.5 & 20.2 & 21.9 & 20.8 \\
\hline & SD & 9.6 & $5.50,12.0$ & 169 & 3.3 & 10.1 & 614 & 0.78 & 4.9 & 7.1 & 6.6 & 5.4 & 5 \\
\hline & $n$ & 6 & 6 & 6 & 5 & 6 & 5 & 6 & 6 & 6 & 6 & 6 & 6 \\
\hline 20 & Mean & 52.5 & 7.03 & 1019 & 37.1 & 23.7 & 1528 & 4.38 & 21.9 & 28.5 & 29.2 & 29.5 & 30.8 \\
\hline \multirow[t]{2}{*}{$(\text { older })^{\mathrm{c}}$} & SD & 22.8 & $6.00,8.00$ & 469 & 4.4 & 11.4 & 532 & 1.41 & 7.2 & 10.1 & 12.2 & 15.3 & 15.5 \\
\hline & $n$ & 6 & 6 & 6 & 4 & 6 & 4 & 6 & 6 & 6 & 6 & 6 & 6 \\
\hline \multirow[t]{3}{*}{40} & Mean & 74.5 & 8 & 1346 & 34.3 & 34.7 & 1611 & NA & 36.9 & 49.9 & 44.1 & 46.3 & 45 \\
\hline & SD & 36.2 & $6.00,10.0$ & 570 & 7.3 & 15 & 496 & NA & 12 & 19.7 & 18.9 & 21.3 & 15.3 \\
\hline & $n$ & 6 & 6 & 6 & 6 & 6 & 6 & NA & 6 & 6 & 6 & 6 & 6 \\
\hline
\end{tabular}

$A R$ accumulation ratio (calculated using $\mathrm{AUC}_{0-24}$ on day 14 vs day 1), $A U C_{0-24}$ area under the concentration-time curve from time 0 to $24 \mathrm{~h}$, $C L / F$ oral clearance, $C_{\max }$ maximum concentration, $C_{\text {trough }}$ trough concentration (obtained prior to dosing on indicated days), NA not applicable, $S D$ standard deviation, $t_{1 / 2}$ terminal elimination half-life, $T_{\max }$ time to maximum concentration, $V_{Z} / F$ oral volume of distribution during terminal phase

${ }^{a}$ Day 14 of dosing for the 40-mg treatment arm corresponds to study day 17

${ }^{\mathrm{b}}$ Median (minimum, maximum)

${ }^{c}$ Healthy subjects aged $56-65$ years

ESM). A two-compartment model with absorption lag, first-order absorption, and elimination provided the best structural fit to the data, based on the minimum value of the objective function, diagnostic plots (Fig. 1 of the ESM), and the precision of parameter estimates. The model was parameterized with CL/F, $V_{1} / F$, volume of distribution of the peripheral compartment, inter-compartmental clearance, and an absorption rate constant. The effects of covariates on the absorption lag, absorption rate constant, inter-compartmental clearance, and volume of distribution of the peripheral compartment were not characterized because of limited data from the sparsely sampled phase II studies.

Covariates of age (18-65 years), weight (43.1-157 kg), and creatinine clearance $(45.2-201 \mathrm{~mL} / \mathrm{min})$ did not have statistically significant associations with either $\mathrm{CL} / \mathrm{F}$ or $V_{1} / F$ (Table 5). In contrast, both sex and smoking status had statistically significant associations with $\mathrm{CL} / \mathrm{F}$, and sex had a statistically significant association with $V_{1} / F$ (Table 5). Male subjects had an increased CL/F and $V_{1} / F$, resulting in approximately $33 \%$ lower ampreloxetine exposure compared with female subjects (Fig. 2a). Similarly, subjects who were smokers had increased CL/F compared with non-smokers, resulting in approximately $32 \%$ lower ampreloxetine exposure in smokers compared with non-smokers for male as well as female subjects (Fig. 2a). No differences in ampreloxetine exposure were observed between the healthy volunteers vs subjects with ADHD or FM (Fig. 2b). Despite the statistical significance of sex and smoking covariates, the differences in ampreloxetine exposure between male smokers, male non-smokers, female smokers, and female non-smokers demonstrated a significant overlap due to the inter-individual variability of ampreloxetine exposure within each subgroup (Fig. 3a).

\subsection{Population Pharmacokinetic-Pharmacodynamic Predictions}

The individually predicted steady-state ampreloxetine exposures following a 5-mg once-daily regimen and a $10-\mathrm{mg}$ once-daily dosing regimen were simulated for 499 subjects (Fig. 3a). Predicted exposures were highest in the female non-smoker group, followed by comparable exposures between female smokers and male non-smokers, with the lowest exposures in male smokers. The predicted pharmacodynamic effect (steady-state NET occupancy) for the ampreloxetine 5-mg group has a range of $71-95 \%$ in the female non-smoker group, $62-93 \%$ in female smokers and male non-smokers, and $63-85 \%$ in male smokers. However, at the $10-\mathrm{mg}$ dose level, the predicted population pharmacodynamic effect was $>75 \%$ NET inhibition in nearly $100 \%$ of the patient population (Fig. 3b). 
Table 3 Summary of mean plasma concentrations $(\mathrm{ng} / \mathrm{mL})$ of ampreloxetine (attentiondeficit/hyperactive disorder study)

\begin{tabular}{|c|c|c|c|c|c|c|}
\hline \multirow[t]{2}{*}{ Treatment arm } & \multirow{2}{*}{$\begin{array}{l}\text { Dose level } \\
\text { (mg) }\end{array}$} & & \multicolumn{4}{|c|}{ PK collection day ${ }^{\mathrm{c}}$} \\
\hline & & & 8 & 15 & 29 & 43 \\
\hline \multirow[t]{6}{*}{ Ampreloxetine $5 \mathrm{mg}$} & \multirow[t]{6}{*}{5} & Mean & 4.53 & 5.11 & 4.85 & 4.91 \\
\hline & & SD & 2.18 & 2.86 & 3.43 & 3.91 \\
\hline & & $\% \mathrm{CV}$ & 48 & 56 & 71 & 80 \\
\hline & & Min & 1.33 & 0.190 & 0 & 0 \\
\hline & & Max & 10.2 & 13.5 & 17.4 & 17.5 \\
\hline & & $n$ & 93 & 91 & 85 & 81 \\
\hline \multirow[t]{12}{*}{ Ampreloxetine $20 \mathrm{mg}$} & \multirow[t]{6}{*}{$10^{\mathrm{a}}$} & Mean & 13.4 & 13.2 & 12.0 & 12.4 \\
\hline & & SD & 6.50 & 6.20 & 7.76 & 10.0 \\
\hline & & $\% \mathrm{CV}$ & 48 & 47 & 65 & 81 \\
\hline & & Min & 4.72 & 4.74 & 1.27 & 3.55 \\
\hline & & Max & 27.5 & 24.1 & 27.9 & 41.0 \\
\hline & & $n$ & 14 & 13 & 13 & 13 \\
\hline & \multirow[t]{6}{*}{$20^{\mathrm{b}}$} & Mean & 9.29 & 20.1 & 20.3 & 18.2 \\
\hline & & SD & 4.50 & 11.2 & 13.4 & 14.9 \\
\hline & & $\% \mathrm{CV}$ & 48 & 56 & 66 & 82 \\
\hline & & Min & 1.37 & 0.208 & 0 & 0 \\
\hline & & Max & 21.1 & 56.4 & 63.4 & 81.2 \\
\hline & & $n$ & 79 & 75 & 66 & 66 \\
\hline
\end{tabular}

$C V$ coefficient of variability, Max maximum, Min minimum, $P K$ pharmacokinetic, $S D$ standard deviation

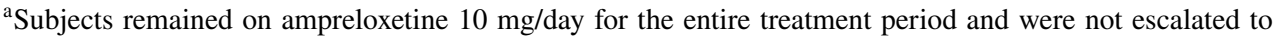
$20 \mathrm{mg}$

${ }^{\mathrm{b}}$ Subjects received $10 \mathrm{mg} /$ day on days 1 through 7 and then on day 8 were escalated to ampreloxetine $20 \mathrm{mg} /$ day for the remainder of the treatment period

${ }^{\mathrm{c}}$ Collection time was random prior to dosing, between 2 and $10 \mathrm{~h}$
Table 4 Summary of mean plasma concentrations (ng/mL) of ampreloxetine (fibromyalgia study)

\begin{tabular}{lllll}
\hline Treatment arm & \multicolumn{3}{l}{ PK collection day } & \\
\cline { 2 - 5 } & 8 & 15 & 29 & 43 \\
\hline Ampreloxetine 5 mg & & & & \\
Mean & 2.42 & 6.32 & 5.54 & 5.31 \\
SD & 1.43 & 3.39 & 3.67 & 3.63 \\
\%CV & 59 & 54 & 66 & 68 \\
Min & 0 & 0 & 0 & 0 \\
Median & 2.45 & 5.99 & 5.07 & 5.15 \\
Max & 7.10 & 15.4 & 15.2 & 13.7 \\
$n$ & 112 & 107 & 100 & 98 \\
Ampreloxetine 20 mg & & & & \\
Mean & 9.93 & 28.0 & 23.4 & 21.0 \\
SD & 6.06 & 16.1 & 16.1 & 15.5 \\
$\%$ CV & 61 & 58 & 69 & 74 \\
Min & 0 & 0 & 0 & 0 \\
Median & 9.33 & 26.6 & 22.6 & 18.0 \\
Max & 24.8 & 79.0 & 87.2 & 76.3 \\
$n$ & 113 & 107 & 93 & 90 \\
\hline
\end{tabular}

$C V$ coefficient of variability, Min minimum, Max maximum, $P K$ pharmacokinetic, $S D$ standard deviation
Table 5 Population pharmacokinetic analysis

\begin{tabular}{lrl}
\hline Description & $\begin{array}{l}\text { Population } \\
\text { estimate } \\
\text { (\%RSE) }\end{array}$ & $\begin{array}{l}\text { Inter-subject } \\
\text { variability \%CV } \\
\text { (\%RSE) }\end{array}$ \\
\hline Dose lag (h) & $1.74(1.52)$ & - \\
$\mathrm{CL} / \mathrm{F}(\mathrm{L} / \mathrm{h})$ & $47.2(3.72)$ & $50.4(10.9)$ \\
$V_{1} / F(\mathrm{~L})$ & $2040(6.25)$ & $38.4(31.9)$ \\
$Q / F(\mathrm{~L} / \mathrm{h})$ & $15.4(20.1)$ & - \\
$V_{2} / F(\mathrm{~L})$ & $357(16.6)$ & - \\
$\mathrm{Ka}(\mathrm{L} / \mathrm{h})$ & $0.2(7.17)$ & $34.1(48.1)$ \\
Sex effect on CL [if female] $(\mathrm{L} / \mathrm{h})$ & $-16.9(11.6)$ & - \\
Smoking effect on CL $(\mathrm{L} / \mathrm{h})$ & $16.0(16.1)$ & - \\
Sex effect on $V_{1}[$ if female] $(\mathrm{L})$ & $-720.0(18.1)$ & - \\
Proportional residual error $(\%)$ & $24.7(8.7)$ & \\
Additive residual error $(\mathrm{ng} / \mathrm{mL})$ & $0.199(24.0)$ &
\end{tabular}

$C L$ clearance, $C L / F$ oral clearance, $C V$ coefficient of variability, $\mathrm{Ka}$ absorption rate constant, $P K$ pharmacokinetics, $Q / F$ inter-compartmental clearance, $R S E$ relative standard error, $V_{l}$ volume central compartment, $V_{l} / F$ volume of distribution of the central compartment, $V_{2} / F$ volume of distribution of the peripheral compartment 

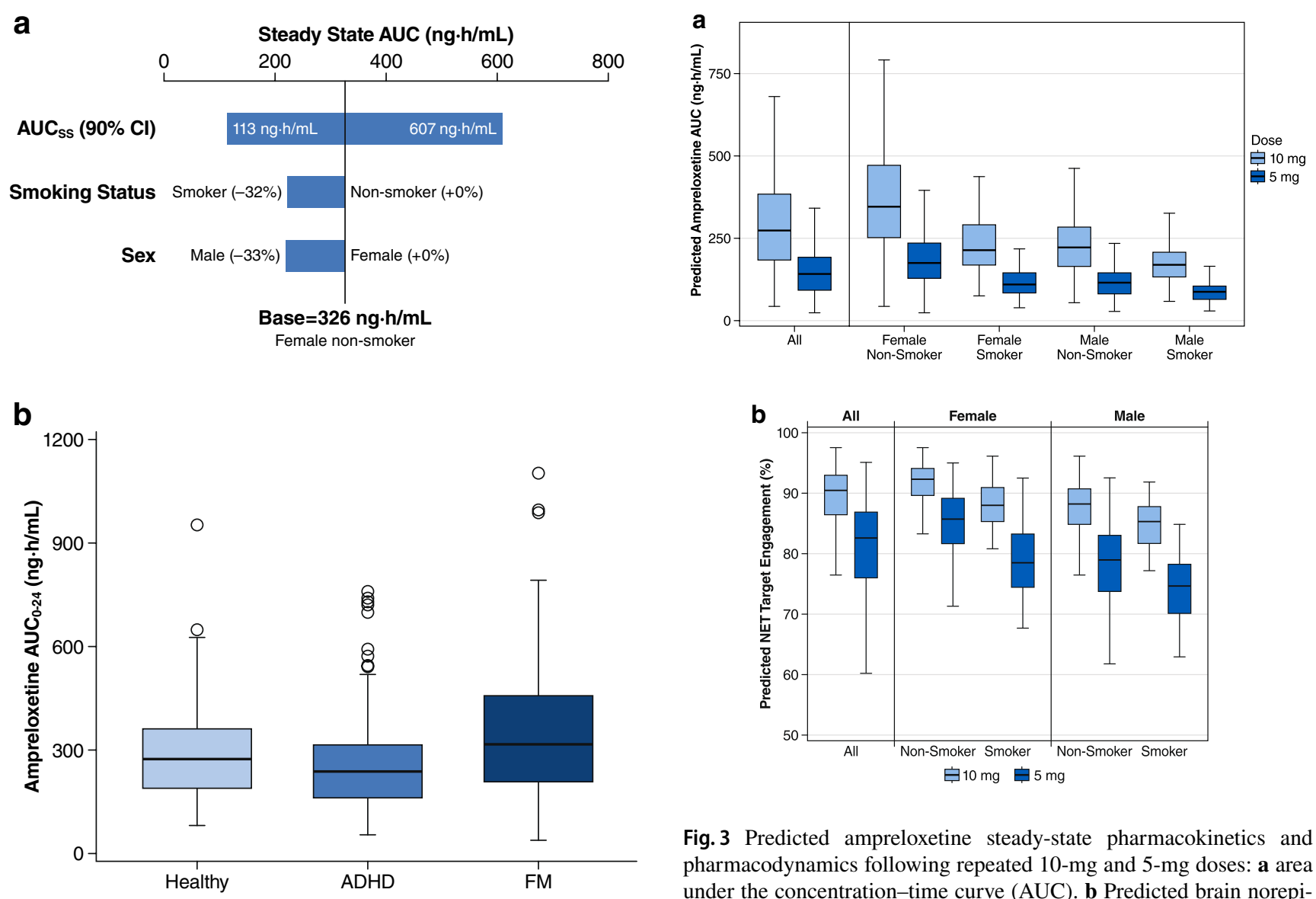

Fig. 3 Predicted ampreloxetine steady-state pharmacokinetics and pharmacodynamics following repeated 10-mg and 5-mg doses: a area under the concentration-time curve (AUC). b Predicted brain norepinephrine transporter (NET) occupancy at an average plasma concentration of ampreloxetine. The solid black line denotes the median; the top and the bottom of the box denote the first and third quartiles; the

Fig. 2 Effect of covariates on the model-predicted ampreloxetine exposure following repeated 10-mg once-daily dosing: a sensitivity plot comparing the effect of significant covariates, $\mathbf{b}$ grouped by disease state. Base, as represented by the black vertical line, refers to the predicted typical area under the concentration-time curve from time 0 to $24 \mathrm{~h}\left(\mathrm{AUC}_{0-24}\right)$ in a female non-smoker from the population pharmacokinetic model. The top horizontal bar with values at each end shows the 5th to 95th percentile $\mathrm{AUC}_{0-24}$ range across the entire population. The middle and lower horizontal bars represent the influence of a single categorical covariate on $\mathrm{AUC}_{0-24}$, with one subject created from each category with other covariates fixed at the typical values for the base subject. The solid black line denotes the median; the top and the bottom of the box denote the first and third quartiles; the whiskers denote 1.5 times the interquartile range. $A D H D$ attention-deficit/hyperactivity disorder, $A U C_{s s} \mathrm{AUC}$ at steady state, $C I$ confidence interval, FM fibromyalgia

\section{Discussion}

Dose selection for phase II and phase III studies is influenced by many factors, and drug pharmacokinetics plays a central role in the dose-selection rationale and concomitant medication strategy. The objectives of this population PK analysis were to define the pharmacokinetics of ampreloxetine and identify covariates to inform dose selection for clinical development in subjects with symptomatic nOH.

Following oral administration, the pharmacokinetics of ampreloxetine was best characterized by a two-compartment PK model with first-order absorption and elimination. Dose proportionality observed in the population PK model was consistent with the results from the non-compartmental analysis of the SAD and MAD studies. Pharmacokinetic profiles were similar in healthy subjects and subjects with ADHD and FM, allowing for direct translation of clinical pharmacology study results in healthy volunteers to patient populations. Following once-daily dosing, ampreloxetine exposure reached steady state by day 6 and accumulated three- to four-fold, consistent with an ampreloxetine elimination half-life of 30-40 h. Accordingly, ampreloxetine exposure maintained a relatively flat drug concentration profile throughout the 24-h dosing interval at steady state. The low peak-to-trough ratio provides the potential for more sustained maintenance of stable orthostatic blood pressure throughout the entire 24-h dosing interval unlike the shortacting standard-of-care agents such as midrodrine [6] and 
droxidopa [7] used for treating symptomatic nOH. Furthermore, the once-daily dosing regimen for ampreloxetine is also anticipated to increase patient compliance [21] relative to midrodine [6] and droxidopa [7], which need to be administered three times a day owing to their short half-lives.

The population PK analysis of all the phase I and phase II clinical data indicates that the covariates of age, weight, or renal impairment (creatinine clearance in the range of mildto-moderate renal impairment) did not impact ampreloxetine exposure. No differences in ampreloxetine exposure were observed based on the CYP2D6 phenotype and thus, the CYP2D6 enzyme is expected to have a negligible contribution towards ampreloxetine metabolism. Accordingly, the same dose is recommended for subjects across all age groups, CYP2D6 phenotype, irrespective of baseline weight or body mass index and inclusive of subjects with mild and moderate renal impairment.

Sex and smoking status were statistically significant covariates shown to impact $\mathrm{CL} / \mathrm{F}$ and $V_{1} / F$. Male subjects demonstrated an $33 \%$ lower ampreloxetine exposure compared with female subjects, while smokers demonstrated an $\sim 32 \%$ lower ampreloxetine exposure compared with nonsmokers for both male and female subjects. These covariates indicate that CYP1A2-based metabolism is the key mechanism for ampreloxetine elimination because smoking is known to induce CYP1A2 activity [22]. Accordingly, a clinical drug-drug interaction study with a CYP1A2 inhibitor and inducer will be conducted with ampreloxetine.

Despite the statistical significance of the covariate effect, ampreloxetine exposure in each of the subgroups including male smokers, male non-smokers, female smokers, and female non-smokers overlaps significantly, and predicted NET brain occupancy is still anticipated to be greater than $75 \%$ at the ampreloxetine 10-mg dose for all subjects. Thus, no difference in the safety and efficacy profile is expected across the subgroups, and no dose adjustment based on sex or smoking status is recommended for clinical development.

\section{Conclusions}

The proposed population PK model effectively described the plasma concentration-time profile of ampreloxetine after single and multiple doses in both healthy subjects and subjects with ADHD and FM. While the covariates included in the model were useful for interpreting inter-individual variability in the data, and providing a rationale for dose selection, dose adjustment in future clinical studies is not warranted. Based on the PK/pharmacodynamic profile of ampreloxetine, a once-daily $10-\mathrm{mg}$ dose is recommended as the optimal dosage to inhibit NET significantly in a majority of the intended patient population.
Author contributions $\mathrm{AL}, \mathrm{RMB}$, and JK designed the research, performed the research, analyzed the data, and wrote the manuscript. DB and RG designed the research, performed the research, and wrote the manuscript.

\section{Compliance with Ethical Standards}

Funding This study was funded by Theravance Biopharma, Inc. Kirsty Nahm MD of The Curry Rockefeller Group, LLC provided assistance with writing/formatting/proofreading/collation of the author comments and this assistance was funded by Theravance Biopharma, Inc. Open access publication of this manuscript was sponsored by Theravance Biopharma, Inc.

Conflict of interest Jitendra Kanodia, Arthur Lo, R. Michael Baldwin, Richard A. Graham, and David L. Bourdet are current or former employees of Theravance Biopharma US, Inc.

Ethics approval All procedures performed in studies involving human participants were in accordance with the ethical standards of the institutional and/or national research committee and with the 1964 Helsinki Declaration and its later amendments or comparable ethical standards.

Consent to participate Informed consent was obtained from all individual participants in the study.

Data sharing Theravance Biopharma, Inc. (and its affiliates) will not be sharing individual de-identified participant data or other relevant study documents.

Open Access This article is licensed under a Creative Commons Attribution-NonCommercial 4.0 International License, which permits any non-commercial use, sharing, adaptation, distribution and reproduction in any medium or format, as long as you give appropriate credit to the original author(s) and the source, provide a link to the Creative Commons licence, and indicate if changes were made. The images or other third party material in this article are included in the article's Creative Commons licence, unless indicated otherwise in a credit line to the material. If material is not included in the article's Creative Commons licence and your intended use is not permitted by statutory regulation or exceeds the permitted use, you will need to obtain permission directly from the copyright holder. To view a copy of this licence, visit http://creativecommons.org/licenses/by-nc/4.0/.

\section{References}

1. Smith JA, Bourdet DL, Daniels OT, Ding YS, Gallezot JD, Henry $\mathrm{S}$, et al. Preclinical to clinical translation of CNS transporter occupancy of TD-9855, a novel norepinephrine and serotonin reuptake inhibitor. Int J Neuropsychopharmacol. 2015;18(2):pyu027.

2. Hegde S, Pulido-Rios M, McNamara A, Smith J, Smith W, Kanodia J, et al. Preclinical cardiovascular sympathoexcitatory effects of TD-9855, a novel norepinephrine transporter (NET) inhibitor in development for the treatment of symptomatic neurogenic orthostatic hypotension $(\mathrm{nOH})$ in subjects with primary autonomic failure [abstract]. Mov Disord. 2018;33(Suppl. 2):S748.

3. Kaufmann H, Biaggioni I, Chatamra K, Panneerselvam P, Haumann B, Vickery R. A Phase 2 study of the efficacy, durability, and safety of ampreloxetine (TD-9855), a norepinephrine reuptake inhibitor, given once-daily to treat neurogenic orthostatic hypotension $(\mathrm{nOH})$ in subjects with synucleinopathies. Poster presented 
at the International Parkinson and Movement Disorder Society; 22-26 September 2019; Nice.

4. Metzler M, Duerr S, Granata R, Krismer F, Robertson D, Wenning GK. Neurogenic orthostatic hypotension: pathophysiology, evaluation, and management. J Neurol. 2013;260(9):2212-9.

5. Florinef (fludrocortisone acetate) [package insert]. Bristol: Monarch Pharmaceuticals, Inc,; 2003.

6. ProAmatine (midodrine) [package insert]. Lexington: Shire US Inc., 2017.

7. Northera (droxidopa) [package insert]. Deerfield: Lundbeck NA Ltd., 2017.

8. Eschlböck S, Wenning G, Fanciulli A. Evidence-based treatment of neurogenic orthostatic hypotension and related symptoms. J Neural Transm (Vienna). 2017;124(12):1567-605.

9. Palma JA, Kaufman H. Epidemiology, diagnosis, and management of neurogenic orthostatic hypotension. Mov Disord Clin Pract. 2017;4(3):298-308.

10. Kaufmann H, Freeman R, Biaggioni I, Low P, Pedder S, Hewitt LA, et al. Droxidopa for neurogenic orthostatic hypotension: a randomized, placebo-controlled, phase 3 trial. Neurology. 2014;83(4):328-35.

11. Hauser RA, Isaacson S, Lisk JP, Hewitt LA, Rouse G. Droxidopa for the short-term treatment of symptomatic neurogenic orthostatic hypotension in Parkinson's disease (nOH306B). Mov Disord. 2015;30(5):646-54.

12. Biaggioni I, Freeman R, Mathias CP, Low P, Hewitt LA, Kaufmann $\mathrm{H}$, et al. Randomized withdrawal study of subjects with symptomatic neurogenic orthostatic hypotension responsive to droxidopa. Hypertension. 2015;65(1):101-7.

13. Shibao C, Raj SR, Gamoa A, Diedrich A, Choi L, Black BK, et al. Norepinephrine transporter blockade with atomoxetine induces hypertension in patients with impaired autonomic function. Hypertension. 2007;50(1):47-53.

14. Strattera (atomoxetine hydrochloride) [package insert]. Indianapolis: Eli Lilly and Company; 2017.
15. Yeola S, Bolleddula J, Brassil P, Worboys P, Bourdet D. Absorption, metabolism, and excretion of $\left[{ }^{14} \mathrm{C}\right] \mathrm{TD}-9855$ after single oral administration to healthy human subjects. Poster presented at the American Association of Pharmaceutical Scientists; 13-17 November 2016; Denver (CO).

16. World Medical Association. Declaration of Helsinki: recommendations guiding doctors in clinical research. Ferney-Voltaire: World Medical Association; 1964.

17. US Department of Health and Human Services, Food and Drug Administration, Center for Drug Evaluation and Research. Assessing the effect of food and drugs in INDs and NDAs: clinical pharamacology considerations. Guidance for industry. February 2019. Available from: https://www.fda.gov/media/121313/download. Accessed 15 June 2020.

18. Adler L, Spencer T. The adult ADHD Clinical Diagnostic Scale (ACDS). New York: New York University School of Medicine; 2004.

19. Crews KR, Gaedigk A, Dunnenberger HM, Leeder JS, Klein TE, Caudle KE, et al. Clinical Pharmacogenetics Implementation Consortium guidelines for cytochrome P450 2D6 genotype and codeine therapy: 2014 update. Clin Pharmacol Ther. 2014;95(4):376-82.

20. Wolfe F, Smythe HA, Yunus MB, Bennett RM, Bombardier C, Goldenberg DL, et al. The American College of Rheumatology 1990 criteria for the classification of fibromyalgia: report of the Multicenter Criteria Committee. Arthritis Rheum. 1990;33(2):160-72.

21. Srivastava K, Arora A, Kataria A, Cappelleri JC, Sadosky A, Peterson AM. Impact of reducing dosing frequency on adherence to oral therapies: a literature review and meta-analysis. Patient Prefer Adher. 2013;7:419-34.

22. Faber MS, Jetter A, Fuhr U. Assessment of CYP1A2 activity in clinical practice: why, how, when? Basic Clin Pharmacol Toxicol. 2005;97(3):125-34. 